\title{
Effectiveness of mechanical thrombectomy in cancer-related stroke and associated factors with unfavorable outcome
}

\author{
Eung-Joon Lee ${ }^{1 \dagger}$, Jeonghoon Bae ${ }^{1 \dagger}$, Hae-Bong Jeong ${ }^{2}$, Eun Ji Lee ${ }^{3}$, Han-Yeong Jeong ${ }^{1}$ and Byung-Woo Yoon ${ }^{1 *}$
}

\begin{abstract}
Background: The effectiveness of mechanical thrombectomy (MT) in cancer-related stroke (CRS) is largely unknown. This study aims to investigate the clinical and radiological outcomes of MT in CRS patients. We also explored the factors that independently affect functional outcomes of patients with CRS after MT.
\end{abstract}

Methods: We retrospectively reviewed 341 patients who underwent MT after acute ischemic stroke onset between May 2014 and May 2020. We classified the patients into CRS $(n=34)$ and control $(n=307)$ groups and compared their clinical details. Among CRS patients, we analyzed the groups with and without good outcomes (3-months modified Rankin scale [mRS] score 0, 1,2). Multivariate analysis was performed to investigate the independent predictors of unfavorable outcomes in patients with CRS after MT.

Results: A total of 341 acute ischemic stroke patients received MT, of whom 34 (9.9\%) had CRS. Although the baseline National institute of health stroke scale (NIHSS) score and the rate of successful recanalization was not significantly different between CRS patients and control group, CRS patients showed more any cerebral hemorrhage after MT (41.2\% vs. controls $23.8 \%, p=0.037)$ and unfavorable functional outcome at 3 months (CRS patients median 3-month mRS score 4, interquartile range [IQR] 2 to 5.25 vs. controls median 3-month mRS score 3, IQR 1 to 4, $[p=0.026]$ ). In the patients with CRS, elevated serum D-dimer level and higher baseline NIHSS score were independently associated with unfavorable functional outcome at 3 months (adjusted odds ratio [aOR]: 1.524, 95\% confidence interval [Cl]: 1.043-2.226; aOR: 1.264, 95\% Cl: 1.010-1.582, respectively).

Conclusions: MT is an appropriate therapeutic treatment for revascularization in CRS patients. However, elevated serum D-dimer levels and higher baseline NIHSS scores were independent predictors of unfavorable outcome. Further research is warranted to evaluate the significance of these predictors.

Keywords: Stroke, Endovascular treatment, Neoplasm, Neoplasm metastasis, Outcome

\section{Introduction}

Cerebrovascular disease affects around $15 \%$ of all patients with malignancy throughout their life. Patients with cancer frequently experience acute ischemic stroke

\footnotetext{
* Correspondence: bwyoon@snu.ac.kr

†Eung-Joon Lee and Jeonghoon Bae contributed equally to this work as cofirst authors.

${ }^{1}$ Department of Neurology, Seoul National University Hospital, 101 Daehak-ro, Jongno-gu, Seoul 03080, Republic of Korea

Full list of author information is available at the end of the article
}

(AIS) [1]. The pathophysiology of AIS in cancer is vary. Among these, cancer-related stroke (CRS) by intravascular coagulopathy by tumor-cell derived cytokines or microparticles, is of particular concern $[2,3]$. Serum Ddimer level is often high $(>1.11 \mu \mathrm{g} / \mathrm{mL})$ and multiple lesions in various vascular territories are associated with CRS $[4,5]$. With the advancement of anti-cancer therapy, the survival period has been prolonged; therefore, CRS and the need for thrombolysis has increased [6].

(c) The Author(s). 2021 Open Access This article is licensed under a Creative Commons Attribution 4.0 International License, which permits use, sharing, adaptation, distribution and reproduction in any medium or format, as long as you give appropriate credit to the original author(s) and the source, provide a link to the Creative Commons licence, and indicate if changes were made. The images or other third party material in this article are included in the article's Creative Commons licence, unless indicated otherwise in a credit line to the material. If material is not included in the article's Creative Commons licence and your intended use is not permitted by statutory regulation or exceeds the permitted use, you will need to obtain permission directly from the copyright holder. To view a copy of this licence, visit http://creativecommons.org/licenses/by/4.0/ The Creative Commons Public Domain Dedication waiver (http://creativecommons.org/publicdomain/zero/1.0/) applies to the data made available in this article, unless otherwise stated in a credit line to the data. 
However, due to conditions such as thrombocytopenia, or recent surgery, patients with CRS are often excluded for intravenous recombinant tissue plasminogen activator (rtPA) administration [7-9]. Therefore, mechanical thrombectomy (MT) for occluded large vessels can be a particularly important treatment option for CRS patients $[10,11]$. However, although there have been earlier studies showing the overall outcomes of MT in patients with CRS [12-17], the effectiveness of MT on CRS remains controversial as patients with active cancer were excluded from previous important clinical trials [18-21]. To the best of our knowledge, there have not been any studies investigating the independent factors associated with the functional outcomes of CRS after MT. Therefore, this study aimed to investigate the effectiveness of MT in CRS patients. We also explored the factors that were independently associated with unfavorable functional outcomes.

\section{Methods}

\section{Subjects}

We retrospectively reviewed the medical records of all 372 consecutive patients with AIS who received MT in the Seoul National University Hospital (SNUH) between May 2014 and May 2020. The following patients were excluded: MT performed > $24 \mathrm{~h}$ after onset; patients with active hematologic malignancies, intracranial neoplasm, or central nervous system metastasis; and patients whose clinical follow-up with a modified Rankin scale (mRS) score at 3-month was unavailable. The final study population was 341. Patients who received MT were divided into two groups: the CRS group and the control. CRS was defined as a cryptogenic ischemic stroke occurring in active cancer patients who had elevated D-dimer levels and/or multiple cerebral territory involvement on diffusion weighted imaging. Active cancer patients referred to those who were diagnosed and currently undergoing or refusing treatment for malignancy. Patients diagnosed during hospitalization for stroke were also included. The involvement of multiple cerebral territories was defined as the presence of multiple ischemic lesions in the unilateral anterior and posterior circulation, bilateral anterior circulation, or bilateral anterior and posterior circulation [22].

This study was approved by the institutional review board (IRB number: 1009-062-332) of SNUH. Informed consent was waived by the IRB due to the retrospective nature of the study.

\section{Clinical assessment}

Age, sex, pre-stroke mRS scores, baseline National Institute of Health Stroke Scale (NIHSS) scores, conventional vascular risk factors (history of hypertension, diabetes mellitus, dyslipidemia, atrial fibrillation, and previous ischemic stroke or transient ischemia attack, coronary artery disease, and smoking status), laboratory findings (hemoglobin level, White blood cells [WBC] count, platelet counts, prothrombin time, total cholesterol level, level of high-density lipoprotein cholesterol [HDL-C], level of low-density lipoprotein cholesterol [LDL-C], and level of C-reactive protein $[\mathrm{CRP}])$, whether the stroke onset is in hospital, occlusion site where the MT was performed, and the status of receiving intravenous rtPA administration of each subject were collected from the database of SNUH's stroke registry. The occluded location was classified into M1 and M2 of middle cerebral artery (MCA), internal carotid artery (ICA), and posterior circulation (posterior cerebral artery [PCA] and basilar artery $[\mathrm{BA}])$. Regarding the time variable associated with MT, onset-to-puncture time and puncture-toreperfusion time were gathered. When the onset time was unclear, the last normal time was used as the reference and the reperfusion time was defined as the first reperfusion with $\mathrm{mTICI} \geq 2 \mathrm{a}$.

The decision to perform MT was determined based on multimodal computed tomography (CT) such as noncontrast CT, CT angiography, and perfusion CT. Magnetic resonance image (MRI) was additionally used in some cases. Intravenous rtPA was used within $4.5 \mathrm{~h}$ after symptom onset if the patients met the relevant criteria. MT was performed using stent retrievers or a forced suction system selected, depending on the preference of the neurointerventionalists. Unless there was a specific contraindication, all patients underwent an MRI during hospitalization and patients were classified according to the Trial of ORG 10,172 in Acute Stroke Treatment (TOAST) criteria [23]. The choice of antithrombotic agents after MT was decided according to individual cases.

In the CRS group, we additionally collected the location and stage of cancer, presence of systemic metastasis, pathologic type whether adenocarcinoma or not, and serum D-dimer levels. Regarding the indicators of clinical outcomes, mRS score at discharge, NIHSS score at discharge, mRS score at 3 months, mortality during hospitalization and after 3 months, and causes of mortality at 3 months were gathered. We defined unfavorable outcome as a 3-month mRS score $\geq 3$ [24].

\section{Radiologic assessment}

A single neurologist and a single radiologist, blinded to the clinical information, independently analyzed the angiographic data; the recanalization status was evaluated according to the modified thrombolysis in cerebral infarction (mTICI) scale through digital subtraction angiography [25]. Successful recanalization was defined as mTICI $2 \mathrm{~b}$ or 3 . 
Cerebral hemorrhage included any intracerebral or subarachnoid hemorrhage found on the $24 \mathrm{~h}$ follow-up imaging. All patients who received MT were followed up immediately after $24 \mathrm{~h}$ by CT or MRI according to the stroke management protocol of SNUH. Reported hemorrhages were categorized according to the Heidelberg Bleeding Classification (HBC) [26].

\section{Statistical analysis}

Statistical analysis was performed using IBM SPSS version 25 (IBM Corp., Armonk, NY, USA). Data were presented as means and medians with corresponding standard deviations and interquartile ranges, respectively. Univariate analyses (independent sample $t$ test or Mann-Whitney $U$ test for continuous variables, and $x^{2}$ test or Fisher's exact test for categorical variables) were performed to compare demographics, vascular risk factors, laboratory findings, location of stroke onset, use of rtPA, and occlusion site between groups. We also compared radiological results such as reperfusion status and presence of any cerebral hemorrhage. Multivariate models were constructed to investigate what factors independently predicted unfavorable outcomes in the CRS group after MT. A two-sided $P$ value of $<0.05$ was considered statistically significant.

\section{Results}

Baseline characteristics of the total study participants A total of 341 participated in our study. Thirty-four (9.9\%) had CRS, while 307 (90.1\%) had ischemic stroke due to other mechanisms. The mean age of the patients was $68.46 \pm 13.2$ years. Among the total 341 patients, 178 were male (52.2\%). Age, sex, premorbid mRS scores, vascular disease risk factors and baseline NIHSS scores were not significantly different between the CRS and control group, except for history of atrial fibrillation $(0 \%$ vs. $57.0 \%, p<0.001)$. The levels of hemoglobin and platelet count were significantly lower $(10.8 \pm 2.1 \mathrm{~g} / \mathrm{d} \ell$ vs. controls $13.1 \pm 2.1 \mathrm{~g} / \mathrm{d} \ell, 187.7 \pm 105.9 \times 10^{3} / \mu \mathrm{L}$ vs. controls $216.3 \pm 72.3 \times 10^{3} / \mu \mathrm{L}, p<0.001, p<0.001$, respectively). However, leukocyte count and CRP levels were significantly higher $\left(10.7 \pm 6.3 \times 10^{3} / \mu \mathrm{L}\right.$ vs. controls $8.8 \pm$ $3.5 \times 10^{3} / \mu \mathrm{L}, 6.3 \pm 8.2 \mathrm{mg} / \mathrm{d} \ell$ vs. controls $1.5 \pm 3.5 \mathrm{mg} / \mathrm{d} \ell$, $p=0.042, p<0.001$, respectively) in the CRS group. Furthermore, in-hospital stroke was significantly more frequent in the CRS group (32.4\% vs. controls $7.8 \%, \mathrm{p}<$ 0.001 ). There was no significant difference in the level of total cholesterol, triglyceride, HDL-C, LDL-C, occlusion site where MT was performed, and status of receiving intravenous rtPA between the two groups (Table 1).

\section{Comparison of the outcomes of MT between CRS and control groups}

There was no statistically significant difference in time variables such as onset-to-puncture time and punctureto-reperfusion time between two groups. The rate of successful recanalization was not significantly different ( $76.5 \%$ vs. controls $87.6 \%, p=0.103$ ) yet any cerebral hemorrhage was significantly more frequent in the CRS group $(41.2 \%$ vs. controls $23.8 \%, p=0.037)$. Both, immediate clinical outcomes as well as short-term outcomes were all significantly unfavorable in the CRS group (median CRS group mRS score at discharge 5 , interquartile range (IQR) 3 to 5 , controls median $\mathrm{mRS}$ at discharge 3 , IQR 1 to $5, p=0.044$; median CRS group mRS score at 3 months 4 , IQR 2 to 5.25 , controls median $\mathrm{mRS}$ at 3 month 3 , IQR 1 to $4, p=0.026$ ). Mortality during the hospitalization and at 3 months was significantly higher (20.6\% vs. controls $5.9 \%, p=0.009$ and $26.5 \%$ vs. controls $6.8 \%, p<0.001$, respectively) in the CRS group. However, most patients died because of the stroke itself and the causes of mortality at 3 months were not significantly different between two groups. (Table 2).

\section{Baseline characteristics and outcomes according to functional outcomes at 3 months after stroke of CRS patients}

Among a total of 34 patients, only 11 (32.4\%) subjects showed good functional outcome (mRS scores $0-2$ ) at 3 months. In this group, the proportion of men was significantly higher $(81.8 \%$ vs. controls $34.7 \%, p=0.026)$ and exhibited significantly less stroke severity (median baseline NIHSS score 9, IQR 7.5 to 13.5 vs. controls median baseline NIHSS score 20, IQR 17 to 25, $p<0.001$ ). Vascular risk factors, previous use of antithrombotic agents, status of receiving rtPA and occluded site were not significantly different between two groups. Onset-topuncture time, puncture-to-reperfusion time and the rate of successful recanalization rate were not significantly different. However, the group with favorable outcome showed significantly less any cerebral hemorrhage after MT $(9.1 \%$ vs. unfavorable group $60.9 \%, p<0.001)$. There was no significant difference in cancer location and type between the two groups. However, the cancer stage was more aggravated, the systemic metastasis was more prevalent $(78.3 \%$ vs. favorable group $36.4 \%, p=$ $0.016)$ in the unfavorable group. Lastly, serum D-dimer level were significantly elevated in the unfavorable group (Unfavorable group D-dimer level median $16.95 \mathrm{mg} / \mathrm{dL}$, IQR 14.55 to 26.60 vs. favorable group D-dimer level median $10.7 \mathrm{mg} / \mathrm{dL}$, IQR 6.66 to $17.71 \mathrm{mg} / \mathrm{dL}, p=0.028$, see Table 3). 
Table 1 Baseline characteristics of the total participants

\begin{tabular}{|c|c|c|c|}
\hline & $\begin{array}{l}\text { Cancer-related stroke } \\
n(\%) \text { or mean } \pm \text { SD or median (IQR) }\end{array}$ & $\begin{array}{l}\text { Control } \\
n(\%) \text { or mean } \pm \text { SD or median (IQR) }\end{array}$ & $\begin{array}{l}p \\
\text { value }\end{array}$ \\
\hline Total & $34(100 \%)$ & $307(100 \%)$ & \\
\hline Age, years & $64.5 \pm 11.4$ & $68.9 \pm 14.0$ & 0.124 \\
\hline Sex, male $[n(\%)]$ & $17(50 \%)$ & $161(52.4 \%)$ & 0.921 \\
\hline Premorbid mRS score & $0(0-1.75)$ & $0(0-0)$ & 0.294 \\
\hline Baseline NIHSS score & $18(11-23)$ & $15(8-19)$ & 0.290 \\
\hline \multicolumn{4}{|l|}{ Comorbidities } \\
\hline Hypertension & $22(64.7 \%)$ & 219 (71.3\%) & 0.768 \\
\hline Diabetes & $14(41.1 \%)$ & $106(34.5 \%)$ & 0.621 \\
\hline Hyperlipidemia & $9(26.5 \%)$ & $139(45.3 \%)$ & 0.328 \\
\hline Coronary artery disease & $5(14.7 \%)$ & $59(19.2 \%)$ & 0.142 \\
\hline Prior stroke or TIA & $6(17.7 \%)$ & $82(26.7 \%)$ & 0.306 \\
\hline Smoking & $5(14.7 \%)$ & $92(30.0 \%)$ & 0.072 \\
\hline Atrial fibrillation & $0(0 \%)$ & $175(57.0 \%)$ & $<0.001$ \\
\hline Previous use of antithromboticst & $13(38.2 \%)$ & $98(31.9 \%)$ & 0.336 \\
\hline \multicolumn{4}{|l|}{ Laboratory findings } \\
\hline Hemoglobin, g/dl & $10.8 \pm 2.1$ & $13.1 \pm 2.1$ & $<0.001$ \\
\hline White blood cells, $10^{3} / \mu \mathrm{L}$ & $10.7 \pm 6.3$ & $8.8 \pm 3.5$ & 0.042 \\
\hline Platelet counts, $10^{3} / \mu \mathrm{L}$ & $187.7 \pm 105.9$ & $216.3 \pm 72.3$ & $<0.001$ \\
\hline Prothrombin time, sec/INR & $1.2 \pm 0.2$ & $1.1 \pm 0.3$ & 0.562 \\
\hline Total cholesterol, mg/de & $150.2 \pm 47$ & $160.2 \pm 42.3$ & 0.134 \\
\hline Triglyceride, $\mathrm{mg} / \mathrm{dl}$ & $110.4 \pm 52.7$ & $99.0 \pm 53.5$ & 0.172 \\
\hline HDL cholesterol, mg/dl & $38.1 \pm 17$ & $47.2 \pm 15.1$ & 0.094 \\
\hline LDL cholesterol, mg/dl & $92.1 \pm 32$ & $97.5 \pm 37.5$ & 0.328 \\
\hline C-reactive protein, $\mathrm{mg} / \mathrm{dl}$ & $6.3 \pm 8.2$ & $1.5 \pm 3.5$ & $<0.001$ \\
\hline In-hospital Stroke & $11(32.4 \%)$ & $24(7.8 \%)$ & $<0.001$ \\
\hline \multicolumn{4}{|l|}{ Occlusion site } \\
\hline Middle cerebral artery & $24(70.6 \%)$ & $172(56.0 \%)$ & 0.143 \\
\hline M1 & $18(52.9 \%)$ & $118(38.4 \%)$ & 0.139 \\
\hline M2 & $6(17.6 \%)$ & $54(17.6 \%)$ & 0.993 \\
\hline Anterior cerebral artery & $1(2.9 \%)$ & $16(5.2 \%)$ & 0.478 \\
\hline Posterior cerebral artery/Basilar artery & $4(11.8 \%)$ & $54(17.6 \%)$ & 0.479 \\
\hline Internal carotid artery & $5(14.7 \%)$ & $63(20.5 \%)$ & 0.504 \\
\hline Common carotid artery & $0(0 \%)$ & $2(0.6 \%)$ & 0.998 \\
\hline Use of intravenous rtPA & $9(26.5 \%)$ & $80(26.1 \%)$ & 0.959 \\
\hline
\end{tabular}

Abbreviations: SD standard deviation, IQR interquartile range, $m R S$ modified Rankin scale, NIHSS National institute of health stroke scale, TIA transient ischemic attack, INR international normalized ratio, HDL High-density lipoprotein, LDL low-density lipoprotein, rtPA recombinant tissue plasminogen activator

†Antiplatelets and anticoagulation agents

Factors associated with unfavorable outcome in CRS after MT

In a univariate analysis of CRS patients, the following factors were significantly associated with unfavorable outcomes: higher initial NIHSS score, male gender, higher serum D-dimer level, occlusion of the M2 segment of middle cerebral artery, presence of systemic metastasis and any cerebral hemorrhage after endovascular treatment. In a binary logistic regression analysis (adjusting for demographics and variables achieving a $p$ value of $<0.1$ in the univariate analyses), elevated serum D-dimer level and higher baseline NIHSS score independently predict unfavorable outcome for CRS patients after MT (adjusted odds ratio (aOR): 1.524, 95\% confidence interval (CI): 1.043-2.226; aOR: 1.264 , 95\% CI: $1.010-1.582$, respectively, see Table 4).

\section{Discussion}

In this study, although the rate of successful recanalization was not significantly different between the CRS and control groups, the degree of functional recovery was 
Table 2 The results after mechanical thrombectomy of cancer-related stroke and controls

\begin{tabular}{|c|c|c|c|}
\hline & $\begin{array}{l}\text { Cancer-related stroke } \\
n(\%) \text { or mean } \pm \text { SD or median (IQR) }\end{array}$ & $\begin{array}{l}\text { Controls } \\
n(\%) \text { or mean } \pm \text { SD or median (IQR) }\end{array}$ & $\begin{array}{l}p \\
\text { value }\end{array}$ \\
\hline Total & $34(100 \%)$ & $307(100 \%)$ & \\
\hline \multicolumn{4}{|l|}{ Time variable } \\
\hline Onset-to-puncture time, min & $327.5(170.25-507.5)$ & $330(185-602.5)$ & 0.751 \\
\hline Puncture-to-reperfusion time, min & $66.5(42.5-90.5)$ & $60(41-90)$ & 0.784 \\
\hline \multicolumn{4}{|l|}{ Radiological outcomes } \\
\hline Reperfusion status & & & 0.758 \\
\hline $\mathrm{mTICl} 0,1$ & $2(5.9 \%)$ & $15(4.9 \%)$ & \\
\hline $\mathrm{mTICl} 2 \mathrm{a}$ & $5(14.8 \%)$ & $23(7.5 \%)$ & \\
\hline $\mathrm{mTICl} 2 \mathrm{~b}$ & $14(41.2 \%)$ & $112(36.5 \%)$ & \\
\hline $\mathrm{mTICl} 3$ & $13(38.2 \%)$ & $157(51.1 \%)$ & \\
\hline Successful recanalization & $26(76.5 \%)$ & $269(87.6 \%)$ & 0.103 \\
\hline Any cerebral hemorrhage & $14(41.2 \%)$ & $73(23.8 \%)$ & 0.037 \\
\hline HBC Class 1a & 0 & 4 & \\
\hline HBC Class $1 \mathrm{~b}$ & 2 & 21 & \\
\hline HBC Class 1c & 3 & 18 & \\
\hline HBC Class 2 & 7 & 25 & \\
\hline HBC Class $3 a$ & 0 & 0 & \\
\hline HBC Class 3b & 0 & 0 & \\
\hline HBC Class $3 \mathrm{C}$ & 2 & 5 & \\
\hline HBC Class 3d & 0 & 0 & \\
\hline Craniectomy & $3(21.4 \%)$ & $18(24.6 \%)$ & 0.452 \\
\hline \multicolumn{4}{|l|}{ Clinical outcomes } \\
\hline NIHSS score at discharge & $13(8-30)$ & $5(2-12.5)$ & $<0.001$ \\
\hline mRS score at discharge & $5(3-5)$ & $3(1-5)$ & 0.044 \\
\hline mRS score at 3 months & $4(2-5.25)$ & $3(1-4)$ & 0.026 \\
\hline Mortality during the hospitalization & $7(20.6 \%)$ & $18(5.9 \%)$ & 0.009 \\
\hline Mortality at 3 months & $9(26.5 \%)$ & $21(6.8 \%)$ & $<0.001$ \\
\hline Causes of death at 3 months & & & 0.687 \\
\hline Stroke & 7 & 15 & \\
\hline Sepsis & 1 & 3 & \\
\hline Progression of cancer & 1 & 0 & \\
\hline Others & 0 & 3 & \\
\hline
\end{tabular}

Abbreviations: $S D$ standard deviation, IQR interquartile range, min minutes, $m T I C l$ modified thrombolysis in cerebral infarction, $H B C$ the Heidelberg Bleeding Classification, mRS modified Rankin Scale, NIHSS National institute of health stroke scale

significantly worse in CRS than that of the control group. These were similar to the findings of previous studies conducted on the MT results of patients with active cancer. Generally, recanalization rate was found to be relatively high, but the degree of short-term functional recovery was found to be poor, and a high mortality rate at 3 months was observed. (Table 5).

According to our analysis, most deaths within 3 months $(77.8 \%)$ were related to cerebral infarction and occurred during hospitalization. Similar to our results, Lee et al. reported that most deaths are caused by the ischemic stroke itself rather than the progression of cancer [12]. After stroke, anti-cancer therapy was usually stopped until the stroke stabilized. Further, stroke affects mortality in patients with active cancer by various ways including the termination of malignancy treatment and the worsening of general conditions. Moreover, Oki et al. showed that $92 \%$ of patients with cancer-related stroke died within $1 \mathrm{y}$ after the stroke occurred [17]. In cancer patients, thromboembolism and progression of cancer are major causes of death. Taking all these results into consideration, the cause of death within a short 
Table 3 Baseline characteristics and outcomes according to functional outcomes at 3 months of cancer-related stroke

\begin{tabular}{|c|c|c|c|}
\hline \multirow[t]{2}{*}{ Characteristics } & \multirow{2}{*}{$\begin{array}{l}\text { Favorable outcome } \\
\text { 3-Month mRS score 0-2 }\end{array}$} & \multirow{2}{*}{$\begin{array}{l}\text { Unfavorable outcome } \\
\text { 3-Month mRS score 3-6 }\end{array}$} & \multirow{2}{*}{$\begin{array}{l}p \\
\text { value }\end{array}$} \\
\hline & & & \\
\hline Total & $N=11$ & $N=23$ & \\
\hline Age, year, median (IQR) & $70(57-73.50)$ & $65(59-72.50)$ & 0.690 \\
\hline Male & $9(81.8 \%)$ & $8(34.7 \%)$ & 0.026 \\
\hline Pre mRS score, median (IQR) & $0(0-0)$ & $0(0-2.5)$ & 0.153 \\
\hline Initial NIHSS score, median (IQR) & $9(7.5-13.5)$ & $20(17-25)$ & $<0.001$ \\
\hline \multicolumn{4}{|l|}{ Vascular risk factors } \\
\hline Prior stroke or TIA & $4(36.3 \%)$ & $2(8.7 \%)$ & 0.070 \\
\hline Coronary artery disease & $1(9.1 \%)$ & $4(17.4 \%)$ & 0.507 \\
\hline Hypertension & $7(63.6 \%)$ & $15(65.2 \%)$ & 0.928 \\
\hline Diabetes mellitus & $4(36.4 \%)$ & $8(34.8 \%)$ & 0.928 \\
\hline Dyslipidemia & $4(36.4 \%)$ & $9(39.1 \%)$ & 0.878 \\
\hline Smoking & $3(27.3 \%)$ & $2(8.7 \%)$ & 0.300 \\
\hline Previous use of antithromboticst & $4(30.8 \%)$ & $9(39.1 \%)$ & 0.876 \\
\hline Administration of IV-rtPA & $1(9.1 \%)$ & $8(34.8 \%)$ & 0.214 \\
\hline Occlusion site & & & 0.861 \\
\hline Middle cerebral artery, M1 & $5(45.4 \%)$ & $13(56.5 \%)$ & \\
\hline Middle cerebral artery, M2 & $2(18.2 \%)$ & $4(17.4 \%)$ & \\
\hline Internal carotid artery & $3(27.3 \%)$ & $2(8.7 \%)$ & \\
\hline Anterior cerebral artery & $0(0 \%)$ & $1(4.3 \%)$ & \\
\hline Posterior cerebral artery/Basilar artery & $1(9.1 \%)$ & $3(13.1 \%)$ & \\
\hline In-Hospital Stroke & $4(36.4 \%)$ & $7(30.4 \%)$ & 0.731 \\
\hline \multicolumn{4}{|l|}{ Time variables } \\
\hline Onset-to-puncture time, min, SD & $471(290.24)$ & $364.39(224.31)$ & 0.612 \\
\hline Puncture-to-reperfusion time, min, SD & $74.45(27.48)$ & $80.17(46.13)$ & 0.856 \\
\hline \multicolumn{4}{|l|}{ Radiologic Outcomes } \\
\hline Recanalization status & & & 0.160 \\
\hline $\mathrm{mTICl} 3,2 \mathrm{~b}$ & $11(100 \%)$ & $16(69.6 \%)$ & \\
\hline $\mathrm{mTICl} 2 \mathrm{a}$ & $0(0 \%)$ & $5(21.7 \%)$ & \\
\hline $\mathrm{mTICl} 1,0$ & $0(0 \%)$ & $2(8.7 \%)$ & \\
\hline Any cerebral hemorrhage & $1(9.1 \%)$ & $13(56.5 \%)$ & $<0.001$ \\
\hline Cancer by location & & & 0.510 \\
\hline Pancreatic cancer & $2(18.2 \%)$ & $7(30.4 \%)$ & \\
\hline Lung cancer & $4(36.4 \%)$ & $3(13.0 \%)$ & \\
\hline Bile duct cancer & $2(18.2 \%)$ & $3(13.0 \%)$ & \\
\hline Liver cancer & $1(9.1 \%)$ & $2(8.7 \%)$ & \\
\hline Gastric cancer & $0(0 \%)$ & $2(8.7 \%)$ & \\
\hline Colon cancer & $1(9.1 \%)$ & $2(8.7 \%)$ & \\
\hline Ovarian cancer & 1 (9.1\%) & $2(8.7 \%)$ & \\
\hline Breast cancer & $0(0 \%)$ & $2(8.7 \%)$ & \\
\hline Cancer stage & & & 0.018 \\
\hline III & $7(63.6 \%)$ & $5(21.7 \%)$ & \\
\hline IV & $4(36.4 \%)$ & $18(78.3 \%)$ & \\
\hline
\end{tabular}


Table 3 Baseline characteristics and outcomes according to functional outcomes at 3 months of cancer-related stroke (Continued)

\begin{tabular}{|c|c|c|c|}
\hline \multirow[t]{2}{*}{ Characteristics } & Favorable outcome & Unfavorable outcome & \multirow{2}{*}{$\begin{array}{l}p \\
\text { value }\end{array}$} \\
\hline & 3-Month mRS score 0-2 & 3-Month mRS score 3-6 & \\
\hline Adenocarcinoma & $11(100 \%)$ & $19(82.6 \%)$ & \\
\hline Others & $0(0 \%)$ & $4(17.4 \%)$ & \\
\hline Systemic metastasis & $4(36.4 \%)$ & $18(78.3 \%)$ & 0.016 \\
\hline D-dimer, median (IQR) & $10.7(6.66-17.71)$ & $16.95(14.55-26.60)$ & 0.028 \\
\hline
\end{tabular}

Abbreviations: $m R S$ modified Rankin scale, IQR interquartile range, NIHSS National institute of health stroke scale, TIA transient ischemic attack, IV intravenous, rtPA recombinant tissue plasminogen activator, $\mathrm{mTICI}$ modified thrombolysis in cerebral infarction

†Antiplatelets and anticoagulation agents

period after stroke in the CRS group is often the stroke itself, and the causes of long-term mortality might be the discontinuation of anti-cancer therapy after stroke and the general deconditioning. Therefore, it might be necessary to actively perform MT in a more selected group to achieve functional recovery in CRS, and to continue anti-cancer therapy. In addition, in some cases, MT in CRS could enable an improved quality of life. Further research on a larger scale of long-term prognosis of CRS after MT is needed.

In the comparison of baseline characteristics between the CRS group and the control, hemoglobin level was significantly lower and leukocyte count was significantly elevated in the CRS group. Inadequate hemoglobin level and elevated leukocyte count is frequently associated with cancer and cancer-related coagulopathy [27-29]. These factors are also associated with unfavorable prognosis after stroke [30]. Furthermore, CRP levels were significantly higher in the CRS group than the control group. As an inflammatory marker, higher CRP may reflect acute inflammation which trigger for thromboembolism, or CRP itself is related to coagulation pathway and therefore may activate the cancer-specific prothrombotic mechanisms [31, 32]. In previous studies, higher circulating levels of CRP are associated with unfavorable outcomes in patients with solid malignancies
[33]. Distinctively, CRS is significantly more occurred during hospitalization. This may suggest the possibility that anti-cancer therapies such as chemotherapy and radiotherapy, and various invasive procedures may be related to pathogenesis of CRS [34]. Or, according to the reason for the patients' hospitalization, infection or inflammation may brought about cancer-related coagulopathy. Further research about factors associated with CRS during hospitalization is needed.

Interestingly, even though there is no significant difference in the baseline NIHSS scores, rate of successful recanalization, time variables such as onset-to-puncture time and puncture-to-reperfusion time, and use of rtPA between CRS and control groups, any cerebral hemorrhage after MT was significantly higher in the CRS group. Whether post-procedural hemorrhage occur more frequently in active cancer patients is still debatable $[35,36]$. However, in the case of cancer-related coagulopathy such as disseminated intravascular coagulation, activation of coagulation may lead to exhaustion of platelets and coagulation factors, and eventually bleeding [37]. Also, the platelet count of CRS group is significantly lower than control in our results. In addition, the risk of cerebral hemorrhage may have increased if liver function associated with synthesis of blood coagulation factors is affected by primary or

Table 4 Factors associated with unfavorable outcome (3-month $m R S \geq 3$ ) in cancer-related stroke after mechanical thrombectomy

\begin{tabular}{lllll}
\hline Covariate & Crude OR $(\mathbf{9 5} \% \mathrm{Cl})$ & $\boldsymbol{p}$ value & Adjusted OR*(95\% Cl) & $\boldsymbol{p}$ value \\
\hline Initial NIHSS score & $1.321(1.104-1.580)$ & 0.002 & $1.264(1.010-1.582)$ & 0.041 \\
Pre-stroke mRS score & $2.418(0.916-6.388)$ & 0.075 & $3.207(0.293-35.134)$ & 0.340 \\
Prior stroke or TIA & $0.167(0.025-1.115)$ & 0.065 & $2.380(0.007-14.578)$ & 0.442 \\
Sex (Men) & $0.119(0.020-0.686)$ & 0.017 & $0.771(0.004-5.983)$ & 0.575 \\
Occlusion of MCA, M2 & $0.167(0.025-1.115)$ & 0.065 & $0.077(0.001-1.967)$ & 0.442 \\
Occlusion of ICA & $0.080(0.008-0.835)$ & 0.035 & $0.557(0.006-4.924)$ & 0.798 \\
D-Dimer & $1.617(1.159-2.255)$ & 0.049 & $1.524(1.043-2.226)$ & 0.029 \\
Any cerebral hemorrhage & $15.556(1.690-143.174)$ & 0.015 & $0.676(0.052-18.481)$ & 0.443 \\
Systemic metastasis & $6.300(1.300-30.533)$ & 0.022 & $1.291(0.847-1.967)$ & 0.118 \\
\hline
\end{tabular}

* Adjusted for baseline NIHSS scores, Pre-stroke mRS, Prior history of stroke or TIA, Sex, Occlusion of M2 segment of MCA and ICA, presence of any cerebral hemorrhage and systemic metastasis

Abbreviations: OR odds ratio, $C I$ confidence interval, NIHSS National institute of health stroke scale, TIA Transient ischemia attack, $m R S$ modified Rankin scale, MCA Middle cererbral artery, ICA internal carotid artery 
Table 5 Comparison of the results between present and earlier studies

\begin{tabular}{|c|c|c|c|c|c|c|c|}
\hline Authors & $\begin{array}{l}\text { Lee et al. } \\
\text { [12] }\end{array}$ & $\begin{array}{l}\text { Jung et al. } \\
\text { [13] }\end{array}$ & $\begin{array}{l}\text { Cho et al. } \\
\text { [14] }\end{array}$ & $\begin{array}{l}\text { Sallustio et al. } \\
\text { [15] }\end{array}$ & $\begin{array}{l}\text { Jeon et al. } \\
{[16]}\end{array}$ & $\begin{array}{l}\text { Oki et al. } \\
\text { [17] }\end{array}$ & $\begin{array}{l}\text { Present } \\
\text { report }\end{array}$ \\
\hline Number of cases & 26 & 19 & 27 & 24 & 62 & 12 & 34 \\
\hline Age (years, mean/median) & 63 (median) & 69 (median) & 69 (mean) & 69 (mean) & 70 (median) & 64 (mean) & 64.5 (mean) \\
\hline Male, sex & $18(69.2 \%)$ & $9(47.4 \%)$ & $20(74.1 \%)$ & $8(33.3 \%)$ & $29(46.8 \%)$ & $5(41.7 \%)$ & $17(50 \%)$ \\
\hline Baseline NIHSS (mean/median) & 14 (median) & 16 (median) & 11 (median) & 14.2 (mean) & 15 (median) & 17.2 (mean) & 18 (median) \\
\hline Cancer stage IV (\%) & N/A & $89.5 \%$ & $29.6 \%$ & $41.7 \%$ & $69.4 \%$ & $58.0 \%$ & $64.7 \%$ \\
\hline Prestroke $\mathrm{mRS} \leq 2$ & N/A & N/A & $100.0 \%$ & $95.8 \%$ & N/A & $83.0 \%$ & $88.2 \%$ \\
\hline IV-rtPA & $19.2 \%$ & $15.8 \%$ & $63.0 \%$ & $45.8 \%$ & $14.5 \%$ & $33.0 \%$ & $26.5 \%$ \\
\hline $\begin{array}{l}\text { Punture-to-reperfusion time (min, mean/ } \\
\text { median) }\end{array}$ & $\begin{array}{l}59.5 \\
\text { (median) }\end{array}$ & 30 (median) & N/A & 52.9 (mean) & 29 (median) & 70 (mean) & $\begin{array}{l}66.5 \\
\text { (median) }\end{array}$ \\
\hline Succesful reperfusion (mTICl 2b or 3) & $88.5 \%$ & $63.2 \%$ & $85.2 \%$ & $76.9 \%$ & $75.8 \%$ & $83.0 \%$ & $76.5 \%$ \\
\hline mRS $0-2$ at 3 months & $23.1 \%$ & $15.8 \%$ & $37.0 \%$ & $41.7 \%$ & $17.7 \%$ & $25.0 \%$ & $32.0 \%$ \\
\hline Mortality at 3 months & $30.8 \%$ & $63.2 \%$ & $33.3 \%$ & $29.1 \%$ & $48.4 \%$ & $50.0 \%$ & $26.5 \%$ \\
\hline Mortality at 12 months & N/A & $\mathrm{N} / \mathrm{A}$ & N/A & N/A & N/A & $92.0 \%$ & N/A \\
\hline
\end{tabular}

Abbreviations: NIHSS National Institutes of Health Stroke Scale score, rtPA recombinant tissue plasminogen activator; $m$ TICI modified thrombolysis in cerebral infarction, $m R S$ modified Rankin scale, N/A not available

metastatic cancer. Immediate and short-term clinical outcomes are all significantly unfavorable in CRS group than controls. This may be due to clinical course of cancer itself, or it could be explained by that it was because of cerebral hemorrhage after MT interrupted appropriate management of ischemic stroke.

In the CRS group, the location of cancer varied, however mainly pancreas, lung, and bile ducts. The type of cancer cell was overwhelmingly adenocarcinoma. All CRS patients had advanced-stage III or more. These findings are all consistent with the results of previous studies about CRS [34]. Bang. Et al identified that circulating cancer-cell extracellular vesicles were higher in lung adenocarcinoma and had a direct role in blood clotting [2]. Understanding the features and further research on the pathologic mechanism of CRS is necessary for development of its proper treatment.

Another notable finding of this study was that elevated serum D-dimer level and higher baseline NIHSS scores independently associated with unfavorable outcomes in CRS after MT. As nonspecific biomarker of hypercoagulability, high D-dimer levels have been known to be related to poor prognosis in CRS $[38,39]$. They are also associated with disturbing recanalization and increasing reperfusion injury [40]. Thus, elevated D-dimer levels may also explain the high incidence of intracerebral hemorrhage after MT in CRS. In previous studies, baseline NIHSS scores have been shown to be associated with post-MT prognosis in patients with AIS [41-43]. Therefore, thrombectomy for CRS patients, especially in a case of patients with elevated serum D-dimer level and more severe stroke, needs more judicious decision and great care should be taken to prevent post-procedural cerebral hemorrhage.
The strength of this study is that we analyzed the independently associated factors of unfavorable outcome in patients with CRS after MT. To the best of our knowledge, this is the first study that investigates the predictors of functional outcome within CRS patients after MT. As an emerging subtype of ischemic stroke, CRS is associated with cancer-related coagulopathy and its rates are expected to increase in future. This will encourage further research to take place to better understand and treat the disease.

This study has several limitations. First, it is a retrospective study with a relatively small number of patients from a single center. Larger sample study is needed to elucidate the effectiveness of MT in patients with CRS. Second, a detailed analysis of treatment status of cancer was not sufficiently performed. It was difficult to incorporate this due to the small sample size. Hence, only the location, stage, presence of metastasis and pathologic features of adenocarcinoma were included. Third, among the control group, patients with inactive cancer were not excluded. The effect that inactive cancer might have on stroke occurrence and prognosis is not clear. However, cancer-related coagulopathy is known to have a strong correlation with cancer activity, and the histological features of thrombi are also known to be different between stroke patients with active cancer and inactive cancer [44]. Therefore, we believe that there is little possibility that inactive cancer affected the occurrence and prognosis of the CRS that we focused on. Lastly, although there was no significant difference in the rate of MT performed in the M2 segment between CRS and control groups, it is likely that MT was less frequently performed in the CRS group than in the control group. Due to the medical condition of CRS patients, there are 
cases in which MT cannot be performed in consideration of risks and benefits. However, this study lacks consideration for these cases, including only the cases where MT was performed. These limitations should be considered while interpreting the study results.

\section{Conclusion}

In conclusion, successful recanalization rate was similar in both CRS and control groups with no differences in baseline NIHSS scores and time variables. Thus, for revascularization, MT is an appropriate therapeutic treatment for CRS. However, post procedural intracerebral hemorrhage were more frequent and overall functional outcomes are unfavorable in the CRS group. Careful consideration of the D-dimer level and the baseline stroke severity is necessary when considering MT for patients with CRS. Further research is warranted to evaluate the significance of these predictors.

\section{Abbreviations \\ MT: Mechanical thrombectomy; CRS: Cancer-related stroke; AIS: Acute ischemic stroke; NIHSS: National institute of health stroke scale; aOR: Adjusted odds ratio; Cl: Confidence interval; HBC: The Heidelberg bleeding classification; rtPA: Recombinant tissue plasminogen activator; WBC: White blood cells; HDL-C: High-density lipoprotein cholesterol; LDL- C: Low-density lipoprotein cholesterol; CRP: C-reactive protein; SNUH: Seoul National University Hospital; MCA: Middle cerebral artery; ICA: Internal carotid artery; PCA: Posterior cerebral artery; BA: Basilar artery; CT: Computed tomography; MRI: Magnetic resonance image; mRS: Modified Rankin scale; TOAST: Trial of ORG 10,172 in Acute Stroke Treatment; mTICl: Modified thrombolysis in cerebral infarction; IQR: Interquartile range}

\section{Acknowledgements}

Not applicable.

\section{Consent to participate}

Informed consent was waived by the institutional review board (IRB number: 1009-062-332) of Seoul National University Hospital due to the retrospective study.

\section{Authors' contributions}

EL and JB conceived and designed the study, acquired, and analyzed the data, interpreted the study findings, and drafted the manuscript. HJ conceived and designed the study. EJL analyzed data. HJ supervised and directed the conduct of the study, interpreted the study findings, and critically revised the manuscript. BY critically reviewed the manuscript. All authors had full access to all the data and the accuracy of the data analysis. The authors read and approved the final manuscript.

\section{Funding}

This research was supported by a fund (\#2020ER620200) by the Korea Centers for Disease Control \& Prevention and Clinical Research Society for Stroke, Republic of Korea.

\section{Availability of data and materials}

Available upon reasonable request to the corresponding author

\section{Competing interest}

The authors declare that they have no conflict of interest.

\section{Ethics approva}

The study has been conducted in compliance with the principles of the declaration of Helsinki. The study was approved by the institutional review board (IRB number: 1009-062-332) of Seoul National University Hospital.

\section{Consent for publication}

Not applicable.

\section{Author details}

${ }^{1}$ Department of Neurology, Seoul National University Hospital, 101 Daehak-ro, Jongno-gu, Seoul 03080, Republic of Korea. ${ }^{2}$ Department of Neurology, Chung-Ang University Hospital, Seoul, Republic of Korea. ${ }^{3}$ Department of Radiology, Soonchunhyang University Seoul Hospital, Seoul, Republic of Korea.

Received: 8 December 2020 Accepted: 25 January 2021

Published online: 06 February 2021

\section{References}

1. Grisold W, Oberndorfer S, Struhal W. Stroke and cancer: a review. Acta Neurol Scand. 2009;119(1):1-16

2. Bang OY, Chung J-W, Lee MJ, Seo W-K, Kim G-M, Ahn M-J, Investigators OCS. Cancer-related stroke: an emerging subtype of ischemic stroke with unique pathomechanisms. J Stroke. 2020;22:1.

3. Kim SG, Hong JM, Kim HY, Lee J, Chung P-W, Park K-Y, Kim G-M, Lee KH, Chung C-S, Bang OY. Ischemic stroke in cancer patients with and without conventional mechanisms: a multicenter study in Korea. Stroke. 2010;41(4): 798-801.

4. Wang J-y, G-j Z, S-x Z, Wang K, Hu X-P, Zhang H, Qu L-D. D-dimer> 2.785 $\mu \mathrm{g} / \mathrm{ml}$ and multiple infarcts $\geq 3$ vascular territories are two characteristics of identifying cancer-associated ischemic stroke patients. Neurol Res. 2018; 40(11):948-54

5. Rogers LR. Cerebrovascular complications in cancer patients. Neurol Clin. 2003;21(1):167-92

6. Henley SJ, Ward EM, Scott S, Ma J, Anderson RN, Firth AU, Thomas CC, Islami F, Weir HK, Lewis DR. Annual report to the nation on the status of Cancer, part I: national cancer statistics. Cancer. 2020;126(10):2225-49.

7. Graber JJ, Nayak L, DeAngelis LM. Use of recombinant tissue plasminogen activator in cancer patients with acute stroke. J Neuro-Oncol. 2012;107(3): $571-3$.

8. Casado-Naranjo I, Calle ML, Falcón A, Serrano A, Portilla JC, Ramírez-Moreno JM. Intravenous thrombolysis for acute stroke in patients with cancer. J Neurol Neurosurg Psychiatry. 2011;82(12):1404-5

9. Cappellari M, Carletti M, Micheletti N, Tomelleri G, Ajena D, Moretto G, Bovi $P$. Intravenous alteplase for acute ischemic stroke in patients with current malignant neoplasm. J Neurol Sci. 2013;325(1-2):100-2.

10. Campbell BC, Donnan GA, Lees KR, Hacke W, Khatri P, Hill MD, Goyal M, Mitchell PJ, Saver JL, Diener H-C. Endovascular stent thrombectomy: the new standard of care for large vessel ischaemic stroke. Lancet Neurol. 2015; 14(8):846-54.

11. Powers WJ, Rabinstein AA, Ackerson T, Adeoye OM, Bambakidis NC, Becker K, Biller J, Brown M, Demaerschalk BM, Hoh B. Guidelines for the early management of patients with acute ischemic stroke: 2019 update to the 2018 guidelines for the early management of acute ischemic stroke: a guideline for healthcare professionals from the American Heart Association/ American Stroke Association. Stroke. 2019;50(12):e344-418.

12. Lee D, Lee DH, Suh DC, Kwon HS, Jeong D-E, Kim J-G, Lee J-S, Kim JS, Kang D-W, Jeon S-B. Intra-arterial thrombectomy for acute ischaemic stroke patients with active cancer. J Neurol. 2019;266(9):2286-93.

13. Jung S, Jung C, Hyoung Kim J, Se Choi B, Jung Bae Y, Sunwoo L, Geol Woo H, Young Chang J, Joon Kim B, Han M-K. Procedural and clinical outcomes of endovascular recanalization therapy in patients with cancer-related stroke. Interv Neuroradiol. 2018;24(5):520-8.

14. Cho B-H, Yoon W, Kim J-T, Choi K-H, Kang K-W, Lee J-H, Cho K-H, Park M-S. Outcomes of endovascular treatment in acute ischemic stroke patients with current malignancy. Neurol Sci. 2020;41(2):379-85.

15. Sallustio F, Mascolo AP, Marrama F, Koch G, Alemseged F, Davoli A, Da Ros $V$, Morosetti D, Konda D, Diomedi M. Safety and efficacy of reperfusion therapies for acute ischemic stroke patients with active malignancy. J Stroke Cerebrovasc Dis. 2019;28(8):2287-91.

16. Jeon Y, Baik SH, Jung C, Kim JY, Kim BJ, Kang J, Bae H-J, Kim JH. Mechanical thrombectomy in patients with acute cancer-related stroke: is the stent retriever alone effective? J Neurolnterv Surg. 2020;0:1-6. https://doi.org/1 0.1136/neurintsurg-2020-016144. 
17. Oki S, Kawabori M, Echizenya S, Shimoda Y, Shimbo D, Osanai T, Uchida K, Houkin K. Long-term clinical outcome and prognosis after Thrombectomy in patients with concomitant malignancy. Front Neurol. 2020;11:1188.

18. Campbell BC, Mitchell PJ, Kleinig TJ, Dewey HM, Churilov L, Yassi N, Yan B, Dowling RJ, Parsons MW, Oxley TJ. Endovascular therapy for ischemic stroke with perfusion-imaging selection. N Engl J Med. 2015;372(11):1009-18.

19. Saver JL, Goyal M, Bonafe A, Diener H-C, Levy El, Pereira VM, Albers GW, Cognard C, Cohen DJ, Hacke W. Stent-retriever thrombectomy after intravenous t-PA vs. t-PA alone in stroke. N Engl J Med. 2015;372(24):228595.

20. Jovin TG, Chamorro A, Cobo E, de Miquel MA, Molina CA, Rovira A, San Román L, Serena J, Abilleira S, Ribó M. Thrombectomy within 8 hours after symptom onset in ischemic stroke. N Engl J Med. 2015;372(24):2296-306.

21. Goyal M, Demchuk AM, Menon BK, Eesa M, Rempel JL, Thornton J, Roy D, Jovin TG, Willinsky RA, Sapkota BL. Randomized assessment of rapid endovascular treatment of ischemic stroke. N Engl J Med. 2015;372(11): 1019-30.

22. Kim SJ, Park JH, Lee M-J, Park YG, Ahn M-J, Bang OY. Clues to occult cancer in patients with ischemic stroke. PLoS One. 2012;7(9):e44959.

23. Adams HP Jr, Bendixen BH, Kappelle LJ, Biller J, Love BB, Gordon DL, Marsh E 3rd. Classification of subtype of acute ischemic stroke. Definitions for use in a multicenter clinical trial. TOAST. Trial of Org 10172 in Acute Stroke Treatment. Stroke. 1993;24(1):35-41.

24. Van Swieten J, Koudstaal P, Visser M, Schouten H, Van Gijn J. Interobserver agreement for the assessment of handicap in stroke patients. Stroke. 1988; 19(5):604-7.

25. Fugate J, Klunder A, Kallmes DF. What is meant by "TICl"? Am J Neuroradiol. 2013;34(9):1792-7.

26. von Kummer R, Broderick JP, Campbell BC, Demchuk A, Goyal M, Hill MD, Treurniet KM, Majoie CB, Marquering HA, Mazya MV. The Heidelberg bleeding classification: classification of bleeding events after ischemic stroke and reperfusion therapy. Stroke. 2015;46(10):2981-6.

27. Caro JJ, Salas M, Ward A, Goss G. Anemia as an independent prognostic factor for survival in patients with cancer: a systematic, quantitative review. Cancer. 2001;91(12):2214-21.

28. Knight $\mathrm{K}$, Wade S, Balducci L. Prevalence and outcomes of anemia in cancer: a systematic review of the literature. Am J Med. 2004;116(7):11-26.

29. Trujillo-Santos J, Di Micco P, lannuzzo M, Lecumberri R, Guijarro R, Madridano O, Monreal M, Investigators R. Elevated white blood cell count and outcome in cancer patients with venous thromboembolism. Thromb Haemost. 2008;100(05):905-11.

30. Kim J-M, Jung K-H, Park KH, Lee S-T, Chu K, Roh J-K. Clinical manifestation of cancer related stroke: retrospective case-control study. J Neuro-Oncol. 2013; 111(3):295-301.

31. Cocho D, Gendre J, Boltes A, Espinosa J, Ricciardi AC, Pons J, Jimenez M, Otermin P. Predictors of occult cancer in acute ischemic stroke patients. J Stroke Cerebrovasc Dis. 2015;24(6):1324-8.

32. Kim K, Lee J-H. Risk factors and biomarkers of ischemic stroke in cancer patients. J Stroke. 2014;16(2):91.

33. Allin $\mathrm{KH}$, Nordestgaard BG. Elevated C-reactive protein in the diagnosis, prognosis, and cause of cancer. Crit Rev Clin Lab Sci. 2011;48(4):155-70.

34. Dardiotis E, Aloizou A-M, Markoula S, Siokas V, Tsarouhas K, Tzanakakis G, Libra M, Kyritsis AP, Brotis AG, Aschner M. Cancer-associated stroke: pathophysiology, detection and management. Int J Oncol. 2019;54(3):77996.

35. Murthy SB, Karanth S, Shah S, Shastri A, Rao CPV, Bershad EM, Suarez II. Thrombolysis for acute ischemic stroke in patients with cancer: a population study. Stroke. 2013;44(12):3573-6.

36. Sobolewski P, Brola W, Szczuchniak W, Fudala M, Sobota A. Safety of intravenous thrombolysis for acute ischaemic stroke including concomitant neoplastic disease sufferers-experience from Poland. Int J Clin Pract. 2015; 69(6):666-73.

37. Levi M. Disseminated intravascular coagulation in cancer patients. Best Pract Res Clin Haematol. 2009;22(1):129-36.

38. Guo Y-J, Chang M-H, Chen P-L, Lee Y-S, Chang Y-C, Liao Y-C. Predictive value of plasma D-dimer levels for cancer-related stroke: a 3-year retrospective study. J Stroke Cerebrovasc Dis. 2014;23(4):e249-54.

39. Nam KW, Kim CK, Kim T, An S, Demchuk A, Kim Y, Jung S, Han MK, Ko SB, Yoon BW. D-dimer as a predictor of early neurologic deterioration in cryptogenic stroke with active cancer. Eur J Neurol. 2017;24(1):205-11.
40. Yao T, Tian B-L, Li G, Cui Q, Wang C-F, Zhang Q, Peng B, Gao Y, Zhan Y-Q, Hu D. Elevated plasma D-dimer levels are associated with short-term poor outcome in patients with acute ischemic stroke: a prospective, observational study. BMC Neurol. 2019;19(1):175.

41. Almekhlafi M, Davalos A, Bonafe A, Chapot R, Gralla J, Pereira V, Goyal M. Impact of age and baseline NIHSS scores on clinical outcomes in the mechanical thrombectomy using solitaire FR in acute ischemic stroke study. Am J Neuroradiol. 2014;35(7):1337-40.

42. Nogueira RG, Liebeskind DS, Sung G, Duckwiler G, Smith WS. Predictors of good clinical outcomes, mortality, and successful revascularization in patients with acute ischemic stroke undergoing thrombectomy: pooled analysis of the mechanical embolus removal in cerebral ischemia (MERCI) and multi MERCI trials. Stroke. 2009:40(12):3777-83.

43. Griessenauer CJ, Medin C, Maingard J, Chandra RV, Ng W, Brooks DM, Asadi $\mathrm{H}$, Killer-Oberpfalzer M, Schirmer CM, Moore JM. Endovascular mechanical thrombectomy in large-vessel occlusion ischemic stroke presenting with low national institutes of health stroke scale: systematic review and metaanalysis. World Neurosurg. 2018;110:263-9.

44. Park H, Kim J, Ha J, Hwang IG, Song TJ, Yoo J, Ahn SH, Kim K, Kim BM, Kim DJ. Histological features of intracranial thrombi in stroke patients with cancer. Ann Neurol. 2019;86(1):143-9.

\section{Publisher's Note}

Springer Nature remains neutral with regard to jurisdictional claims in published maps and institutional affiliations.
Ready to submit your research? Choose BMC and benefit from:

- fast, convenient online submission

- thorough peer review by experienced researchers in your field

- rapid publication on acceptance

- support for research data, including large and complex data types

- gold Open Access which fosters wider collaboration and increased citations

- maximum visibility for your research: over $100 \mathrm{M}$ website views per year

At BMC, research is always in progress.

Learn more biomedcentral.com/submissions 